\title{
Efeito da aplicação foliar de extrato de algas, aminoácidos e nutrientes via foliar na produtividade e qualidade de alface crespa ${ }^{1}$
}

\author{
Pâmela Andressa Limberger ${ }^{2}$, Jorge Alberto Gheller ${ }^{3}$
}

\begin{abstract}
${ }^{1}$ Aceito para publicação em $1^{\circ}$ de outubro de 2011
${ }^{2}$ Faculdade Assis Gurgacz - FAG, Curso de Agronomia. Avenida das Torres n. 500, CEP: 85.806-095 Bairro Santa Cruz, Cascavel, PR.

${ }^{3}$ Engenheiro Agrônomo, MSc em Fitossanidade, professor de Fitopatologia II e Defesa Fitossanitária Curso de Agronomia da FAG. Avenida das Torres n. 500, CEP 85.806-095, Bairro Santa Cruz, Cascavel, PR.
\end{abstract}

Palavras-chave: : Lactuca sativa L, bioestimulante, Ascophyllum nodosum, ácido Glutâmico.

\section{Resumo}

O presente trabalho teve por objetivo avaliar os prováveis efeitos da aplicação foliar de extrato de algas, do ácido glutâmico e de nutrientes foliares, no desenvolvimento, na produtividade e no número de folhas produzidas na cultura da alface. $\mathrm{O}$ experimento foi conduzido à campo, num delineamento em blocos casualizados com quatro repetições, com os seguintes tratamentos: 1) bioestimulantes Gold Carrier e Planta 100, $2 \mathrm{ml}$ produto comercial/litro 2) bioestimulante Plenno, $2,5 \mathrm{ml}$ produto comercial/litro 3) bioestimulante Gold Carrier, $2 \mathrm{ml}$ produto comercial/litro; 4) bioestimulantes Algamino, $4 \mathrm{ml}$ do produto comercial/litro 5) bioestimulante Planta 100, $2 \mathrm{ml}$ produto comercial/litro 6) Testemunha (sem aplicação). Foram realizadas três aplicações foliares aos 14, 21 e 28 dias do transplante, utilizando-se o volume de solução equivalente $200 \mathrm{l} / \mathrm{ha}$. Ao final do ciclo da cultura foram quantificados os parâmetros peso individual de planta, o 


\section{A. L. PÂMELA et al.,}

diâmetro de cada planta e o número de folhas. A análise final dos resultados demonstrou significância apenas para número de folhas.

\section{Effect of foliar application of seaweed extract, amino acids and foliar nutrients on productivity and quality of lettuce}

\section{Abstract}

This study aimed to assess the likely effects of foliar application of seaweed extract, glutamic acid and foliar nutrients, development, productivity and number of leaves produced in the culture of lettuce. The field experiment was carried out in a completely randomized design with four replicates with the following treatments. 1) Gold biostimulants Carrier and Plant 100, commercial product 2 $\mathrm{ml} /$ liter 2) biostimulant Plenna, $2.5 \mathrm{ml}$ commercial product / liter 3) biostimulant Gold Carrier, commercial product 2 $\mathrm{ml} /$ liter, 4) biostimulants Algamino, $4 \mathrm{ml}$ of the product commercial / liter 5) biostimulant Plant 100, commercial product $2 \mathrm{ml} /$ liter 6) control (without application). foliar applications were made three to 14,21 and 28 days after transplantation, using the equivalent volume of solution 200 $1 /$ ha . At the end of the crop cycle were quantified individual plant weight, the diameter of each plant and leaf number. The final analysis of the results showed significant, except for number of leaves.

Key words: Lactuca sativa L, plant growth regulator, Ascophyllum nodosum, acid Glutamic. 


\section{A. L. PÂMELA et al.,}

\section{Introdução}

A alface (Lactuca sativa L.) pertence à família Asteraceae, é originária da Ásia e foi trazida para o Brasil pelos portugueses no século XVI. É uma planta típica de clima temperado, porém com cultivares geneticamente melhoradas para uma maior tolerância a temperaturas elevadas, ao pendoamento precoce e a doenças de determinadas épocas, o que possibilita seu cultivo durante todo o ano no Brasil (Monteiro et al, 2005). É uma das hortaliças mais difundidas atualmente, havendo possibilidade de cultivos sucessivos no mesmo ano; devido ao curto ciclo, o baixo custo de produção, a pouca suscetibilidade a pragas e a doenças e a comercialização segura. Tais características fazem com que a alface seja a hortaliça preferida pelos pequenos produtores, o que lhe confere grande importância econômica e social, sendo significativo fator de permanência do homem do campo .

A alface está entre as hortaliças folhosas economicamente mais importantes do mundo, destacando-se o Brasil como maior consumidor da América do Sul. (Pinto et al .,2010).

É considerada uma das hortaliças de folhas mais importante na dieta da população brasileira, sendo consumida principalmente na forma de salada (Viggiano, 1990). Com o aumento da população e também mudança de hábito alimentar, o consumo da alface tem aumentado, tornando-se inevitável o aumento da produção. Além disso, o consumidor tem se tornado mais exigente, havendo necessidade de produzi-la em quantidade e com qualidade, bem como manter o seu fornecimento o ano todo (Barros; et al., 2010). Com uma área cultivada de aproximadamente 30 mil hectares, a produção anual no Brasil é de aproximadamente dois milhões de toneladas (Stapasson et al., 2010). 


\section{A. L. PÂMELA et al.,}

Segundo Mógor \& Cámara, a mão-de-obra necessária para a cultura equivale a $22 \%$ do custo de produção e gera cinco empregos diretos por hectare. O mercado de sementes de alface é estimado em torno de US\$ 2 milhões ano- ${ }^{-1}$ ( Sala \& Costa, 2005).

Atualmente no cultivo intensivo de alface são utilizados diversos produtos para o aumento da produtividade e melhora da qualidade entre eles os aminoácidos, os adubos foliares e produtos a base de algas marinhas.

De acordo com Vieira (2001) é considerado bioestimulante a mistura de dois ou mais reguladores vegetais ou mesmo com outras substâncias de natureza bioquímica como aminoácidos, vitaminas e nutrientes. Produtos obtidos a partir do extrato da alga Ascophyllum nodosum, também tem sido utilizados como bioestimulantes em diversas culturas (Brown, 2004), sendo que, na Comunidade Européia é comum o uso de produtos comerciais à base de extrato de alga nas aplicações foliares ou diretamente no solo. (Mógor et al., 2008).

No Brasil, o uso de produtos a base de extrato de algas na agricultura é regulamentado pelo Decreto no 4.954 (Brasil, 2004) e é enquadrado como agente complexante em formulações de adubos foliares e também utilizado na fertirrigação. Na mesma categoria, enquadra-se o ácido Lglutâmico, aminoácido que é produzido pela fermentação do melaço da cana pela bactéria Corynebacterium glutamicum (Mógor et al.; 2008). A alga marrom Ascophyllum nodosum vem sendo explorada comercialmente, com efeitos positivos no desenvolvimento das plantas (Standik, 2003).

É atribuída aos bioestimulantes a capacidade de estimular as respostas das plantas às doenças e estresses abióticos (Standik, 2003). De acordo com (Pessatti\& Maraschim, 1998), é comumente encontrado polissacarídeos complexos na parede celular de algas, os quais podem apresentar 


\section{A. L. PÂMELA et al.,}

diferentes formas de atividade biológica, como aumentar as respostas de defesa da planta. $\mathrm{O}$ extrato de alga estimula $\mathrm{O}$ crescimento vegetal, pois contém macro e micronutrientes, carboidratos, aminoácidos e estimuladores de crescimento. Segundo (Anasac 2006) as ações conjunta dessas moléculas e nutrientes produzem um efeito estimulante, enquanto Goemar (2006) contatou que a aplicação do extrato de A. nodosum pode melhorar alguns processos fisiológicos das plantas, como absorção de nutrientes e a fotossíntese.

Nesse experimento utilizou-se os bioestimulantes BioGain Algamino, Planta 100, Plenno, Gold Carrier e a mistura de Gold Carrier + Planta 100 .

O BioGain Algamino é um fertilizante organomineral classe A, fluído, líquido, para aplicação foliar e fertirrigação, à base de extrato de algas marinhas e aminoácidos de origem vegetal. Devido à sua composição, promove uma maior formação de raízes, aumenta a floração e a taxa de fecundação. Possui efeito desestressante e desintoxicante nas culturas, fazendo com que as plantas retomem rapidamente seu crescimento. Promove o aumento do teor de clorofila, além de atuar como carreador. (Rigrantec).

O Plenno é um fertilizante mineral contendo cálcio complexado com algas marinhas (Ascophyllum nodosum) e aminoácidos (ácido L-glutâmico), sendo aplicado via foliar objetivando promover maior tolerância das plantas aos estresses ambientais e ao déficit hídrico. (microquímica).

O Planta 100 é um fertilizante foliar contendo aminoácidos com formulação agronomicamente balanceada para nutrir todos os ciclos das culturas frutíferas, hortaliças e gramas. (Nutri flora).

O Gold Carrier é um fertilizante organomineral líquido, altamente solúvel em água de aplicação foliar. É considerado como promotor de crescimento, contendo 


\section{A. L. PÂMELA et al.,}

ácidos naturais como fúlvicos e húmicos. Também é considerado um quelante natural.

O objetivo desse trabalho foi avaliar o efeito de alguns produtos comerciais a base de extrato de algas, ácido Glutâmico e de nutrientes foliares, no desenvolvimento, na produtividade e no número de folhas produzidas na cultura da alface.

\section{Materiais e métodos}

O experimento iniciou-se em maio de 2011, conduzido a campo na área de uma horta comercial situado na Estrada Rio da Paz Km 04, na cidade de Cascavel - PR, cujas coordenadas geográficas são $25^{\circ} 01 ' 31,78$ "s latitude, $53^{\circ} 28^{\prime} 13,64 " w$ e altitude de $622 \mathrm{~m}$. O solo da área onde está situada a horta foi classificado como Latossolo vermelho. Antes do transplante da cultura foi realizado analise química de solo para possíveis correções, sendo que o adubo de base foi determinada mediante o resultado da análise. A variedade utilizada foi a Vanda, pertence ao tipo de folhas crespas, que apresenta um ciclo vegetativo de 55-70 dias, com folhas de coloração verde-claras. A semeadura foi realizada em bandejas de poliestireno, com 200 células. O transplante feito em canteiros em quatro linhas espaçadas de $0,30 \mathrm{~cm}$ e as plantas espaçadas também de $0,30 \mathrm{~cm}$.

Para avaliar o efeito do extrato de alga, do ácido L-glutâmico e de diversos nutrientes foliares em associação foram definidos seis tratamentos: 1) bioestimulantes Gold Carrier e Planta 100, $2 \mathrm{ml}$ de cada produto comercial/litro 2) bioestimulante Plenno, $2,5 \mathrm{ml}$ produto comercial/litro 3) bioestimulante Gold Carrier, $2 \mathrm{ml}$ produto comercial/litro; 4) bioestimulantes Algamino, $4 \mathrm{ml}$ do produto comercial/litro 5) bioestimulante Planta 100, $2 \mathrm{ml}$ produto comercial/litro 6) Testemunha (sem aplicação).

Para a aplicação foliar nas plantas, cada nutriente na dose definida foi diluido em água utilizada 


\section{A. L. PÂMELA et al.,}

normalmente na propriedade e aplicado via foliar com pulverizador costal manual, de capacidade para 20 litros, com regulador de pressão. $\mathrm{O}$ volume utilizado foi equivalente a 200 litros/ha. Foram realizadas três aplicações aos 14, 21 e 28 dias do transplante.

$\mathrm{O}$ delineamento experimental utilizado foi em blocos completamente casualizados, com quatro repetições. Cada unidade amostral foi composta por 24 plantas para cada tratamento, sendo coletadas para avaliação oito plantas em cada uma. As características avaliadas para cada planta colhida foram diâmetro da planta em centímetros, peso fresco em gramas e o número de folhas para cada tratamento. Para esta última característica, foram analisadas quatro plantas.

Os resultados obtidos foram submetidos à analise de variância (teste F) e as médias comparadas pelo teste de Tukey a 5\% de significância, utilizando o programa Sisvar.

\section{Resultados e discussões}

Tabela 1. Efeito da aplicação de bioestimulantes no número de folhas de alface

\begin{tabular}{ll}
\hline Tratamentos & Médias \\
\hline 5 Planta 100 & $21.56 \mathrm{a}$ \\
6 Testemunha & $20.87 \mathrm{ab}$ \\
2 Pleno & $20.75 \mathrm{ab}$ \\
4 Algamino & $20.50 \mathrm{ab}$ \\
3 Gold & $20.12 \mathrm{ab}$ \\
1 Gold+Planta 100 & $19.68 \mathrm{~b}$ \\
\hline CV & $8,32 \%$ \\
\hline
\end{tabular}

Médias seguidas de mesma letra, na coluna, não diferem entre si pelo teste de Tukey a $5 \%$ de probabilidade

Analisando a Tabela 1, verifica-se que o tratamento com o bioestimulante Planta 100 influenciou estatisticamente quanto ao número de folhas, seguido dos tratamentos Testemunha, Plenno, Algamino e Gold Carrier 


\section{A. L. PÂMELA et al.,}

respectivamente. Já o tratamento Gold Carrier mais Planta 100 , resultou inferior aos demais tratamentos, com menor número de folhas.

Supõe-se que, como foi realizada a mistura de dois bioestimulantes para compor o tratamento, pode haver ocorrido inibição de alguns componentes químicos contidos em ambos devido à mistura.

No sistema de produção da alface, o maior número de folhas proporciona maior fotossíntese e por conseqüência maior será o tamanho e volume da planta. Plantas com tais atributos, quando colocadas em embalagens para comercialização, apresentarão maior volume em pacotes avulsos, maior peso e rendimento para produtos processados. Logo o número de folhas presentes em cada planta é um fator importante na apresentação visual e na comercialização, já que o consumidor ao definir sua escolha por esta hortaliça folhosa opta pelas plantas de maior tamanho.

Assim considerando que para a comercialização da cultura da alface, o número de folhas tem importância, pois quanto maior o número de folhas maior será o tamanho da planta, conseqüentemente a venda. Portanto, para este caso foi positivo o uso do produto Planta 100. Segundo (Moreira et.al. 2005), o uso de bioestimulantes a base de algas A. nodosum, teve resultados positivos quanto ao número de folhas, massa fresca, massa seca, altura de caule, sendo contraditório aos resultados obtidos. 
A. L. PÂMELA et al.,

Tabela 2: Peso (g) e diâmetro das plantas (cm)

\begin{tabular}{lll}
\hline Tratamentos & Peso & Diâmetro \\
\hline 1 Gold+Planta & $155.93 \mathrm{a}$ & $32.59 \mathrm{a}$ \\
3 Gold & $160.96 \mathrm{a}$ & $32.87 \mathrm{a}$ \\
6 Testemunha & $161.09 \mathrm{a}$ & $32.82 \mathrm{a}$ \\
2 Pleno & $163.43 \mathrm{a}$ & $32.46 \mathrm{a}$ \\
4 Algamino & $165.81 \mathrm{a}$ & $32.98 \mathrm{a}$ \\
5 Planta 100 & $179.25 \mathrm{a}$ & $33.39 \mathrm{a}$ \\
\hline CV & $22,9 \%$ & $5,75 \%$ \\
\hline
\end{tabular}

Médias seguidas de mesma letra, na coluna, não diferem entre si pelo teste de Tukey a $5 \%$ de probabilidade.

O fator peso individual de cada planta unitária não influi diretamente na preferência da escolha pelo consumidor, todavia influi diretamente na produtividade da cultura. Um produto com maior peso no caso de hortaliças processadas terá maior rendimento para o produtor.

Já o diâmetro de plantas está diretamente associado ao tamanho foliar, sobretudo as basais. Assim pode-se inferir que ao apresentar maior diâmetro a planta terá uma melhor característica de escolha visual, portanto com melhores chances de ser comerciável. Em determinadas épocas do ano, há muita oferta de produto no comércio, o que estabelece exigência dos compradores, o produtor que possuir seu produto com maior tamanho e qualidade é aquele que terá melhor aceitação do mercado e maior valor recebido pelo seu produto, obtendo assim maior rentabilidade.

Os resultados obtidos nos diferentes tratamentos empregados para as variáveis peso individual e diâmetro de plantas apresentaram apenas influência numérica sem, no entanto apresentar influência estatisticamente significativa.

Cogita-se que alguns fatores tenham contribuído para determinação dos resultados. O experimento foi realizado em uma horta tradicional, onde a cada plantio, são realizadas tanto adubação orgânica como a química, 


\section{A. L. PÂMELA et al.,}

portanto resultando num solo extremamente fértil. Assim em conseqüência da situação da elevada fertilidade existente no solo, pressume-se que os tratamentos empregados através da adubação foliar não tenham propiciado efeitos, já que as plantas estavam adequadamente nutridas com os nutrientes existentes nos produtos testados.

Um segundo fator que pode haver afetado os resultados foi o clima reinante durante o experimento. A época que foi implantado e conduzido o experimento coincidiu com a ocorrência de inverno muito rigoroso. No período houve formações de geadas bastante severas, que podem ter influenciado na paralisação do desenvolvimento vegetativo e consequiente menor diâmetro e menor peso fresco. Também possivelmente em função das temperaturas baixas observou-se uma elongação do ciclo cultural, sem, no entanto ocorrer melhoras em diâmetro basal e peso fresco de plantas. Outro fator observado em consequiência das baixas temperaturas havidas foi a ocorrência em incidência elevada da doença conhecida como mofo branco, provocada pelo fungo Sclerotinia sclerotiorum, o qual pode haver contribuído para provocar perdas em qualidade.

Segundo (Mazzarino \& Bortolossi 2010) utilizando extrato de algas Ascophyllum nodosum na cultura do pepino para avaliação da produtividade, constataram diferença significativa quanta uniformidade e quantidade dos frutos. Porém para peso, comprimento e diâmetro de frutos não se obteve diferenças significativas na comparação de médias entre os tratamentos testados, ou seja, o produto a base de extrato de algas não proporcionou ganhos nestas três variáveis.

\section{Conclusões}

Neste experimento, o emprego de bioestimulantes mostrou resultados positivos e significativos para a variável 


\section{A. L. PÂMELA et al.,}

número de folhas produzidas com o emprego do tratamento Planta 100. Já para as variáveis diâmetro e peso unitário de plantas, não obteve-se diferenças significativas na comparação de médias entre os tratamentos testados. Todavia mesmo com resultado promissor, há necessidade de mais estudos aumentando amplitude dos resultados científicos, uma vez que o uso destes produtos a base de algas e aminoácidos, apresentam potencial para a cultura e perspectivas para os produtores.

\section{Referências}

ANASAC. Agrícola Nacional S.A.C. Disponível em: www.anasac.cl.Acesso em: 29 /04/2011

BARROS JÚNIOR AP; BEZERRA NETO F; SILVEIRA LM; LINHARES PCF; MOREIRA JN; LIMA JSS; SANTOS E.C.S; SILVA EO; NUNES MCC. Qualidade pós-colheita de alface em função de diferentes tipos e quantidades de adubos verdes. 2010. Horticultura Brasileira 28: S1351-S1357. Acesso 29/03/2011

BETTONI M. M.; ADAM W. M.; MÓGOR Á. F. Tuberização de batata em função da aplicação de extrato de alga e cobre. Horticultura Brasileira (2008). Acesso $29 / 04 / 2011$

BRASIL. Decreto $\mathrm{n}^{\circ}$. 4.954, de 14 de Janeiro de 2004. Diário Oficial da União, Poder Executivo, Brasília, DF, 15 de jan. 2004. Seção 1, p. 2. Disponível em: <http://extranet.agricultura.gov.br/sislegisconsultaconsultar Legislaca. Acesso em: 14/04/2011. 


\section{A. L. PÂMELA et al.,}

BROWN, M. A. The use of marine derived products and soybean meal in organic vegetable production. $94 \mathrm{p}$. Thesis (Master in Science) - Department of Horticultural Science, North Carolina State University, Raleigh, 2004.

GOËMAR, 2006. Laboratório do mar. Disponível em www.goëmar.com. Acesso em 29/03/2011

MAZZARINO, S.A; BORTOLOSSI, J.L; Eficiência agronômica da alga Ascophyllum nodosum, no acréscimo de produtividade e qualidade na produção da cultura do pepino.

MÒGOR, A. F.; CÂMARA, F. L. Produção de alface no sistema orgânico em sucessão a aveia preta, sobre a palhada em diferentes tipos de solo Horticultura Brasileira (2007). Acesso 16-04-2011.

MÓGOR, A. F.; ONO, E. O.; RODRIGUES, J. D. Aplicação foliar de extrato de alga, ácido l-glutâmico e cálcio em feijoeiro. Horticultura Brasileira (2008).

MONTEIRO, L.A.; MARQUES, G. N.; LOUZADA, R. S.; SCHÖFFEL, E. R.; MENDEZ, M. E. G.; COGO, C. M. Avaliação do crescimento de três cultivares de alface sob cultivo orgânico em ambiente protegido. Horticultura Brasileira Acesso 17-04-2011.

MOREIRA, G.C; HABER. L.L; TONIN. F.B; GOTO. R; VALENTE. M.C; Unesp-FCA, Diferentes aplicações da alga Ascophyllum nodosumno desenvolvimento da alface. Horticultura brasileira (2007). Acesso 09/10/2011 


\section{A. L. PÂMELA et al.,}

PESSATTI, M. L.; MARASCHIN, M. Atividades biológicas e aspectos estruturais de carboidratos de origem marinha. In: JORNADA CATARINENSE DE 36 PLANTAS MEDICINAIS - saúde e sustentabilidade para o $3^{\circ}$ milênio, Anais... Tubarão: Unisul, 183p. p. 47-51. 1998.

PINTO, PAC; SANTOS, NGN; GERMINO GFS; DEON, TD; SILVA, AJ. Eficiência agronômica de extratos concentrados de algas marinhas na produção da alface em Neossolo Flúvico. 2010. Horticultura Brasileira 28: S3980-S3986.

VIGGIANO, Avaliação de cultivares de alface sob altas temperaturas em cultivo protegido em três épocas de plantio (1990) Horticultura Brasileira. Acesso 16-04-2011.

SALA, F.C., COSTA, C.P. PIRAROXA: cultivar de alface crespa de cor vemelha intensa. Horticultura Brasileira, Brasília, v. 23, n. 1, p. 158-159, jan e mar. 2005.

SILVA, T.R.B.; TAVARES, C.A. Aplicação superficial de corretivos no desenvolvimento do milho. In: CONGRESSO BRASILEIRO DE CIÊNCIA DO SOLO, 31, 2007, Gramado. Anais. Gramado: UFPel, 4p.

STAPASSON, E.; Silva, P. T.; MOGOR, A. F. Aplicação foliar de solução contendo extrato de alga, ácido l-glutâmico e cálcio em alface. $\mathbf{5 0}^{\circ}$ Congressos Brasileiro de Olericultura 2010. 

A. L. PÂMELA et al.,

STADNIK, MJ. Uso potencial de algas no controle de doenças de plantas. In: VIII Reunião de Controle Biológico de Fitopatógenos. - Ilhéus: Ceplac, p.70-74. 